\title{
Potential of composite fuel application based on low-grade coal and wastes of forest and flour industry
}

\author{
Stanislav Jankovsky ${ }^{1, *}$, Anton Tolokolnikov ${ }^{1}$, and Konstantin Slyusarskiy ${ }^{1}$ \\ ${ }^{1}$ National Research Tomsk polytechnic university, 634050 Tomsk, Russia
}

\begin{abstract}
Composite fuels based on low-grade brown coal of 3B-grade mixed with forest and flour industry wastes were studied. Three compositions with similar weight content of forest industry waste and low-grade coal as well as flour industry waste in concentration range from 0 to 15 wt. \%. The chemical properties and ignition characteristics of samples were studied by means of TG-analysis at air medium and $10 \mathrm{~K} / \mathrm{min}$ heating rate in temperature range $50-600{ }^{\circ} \mathrm{C}$. The samples with $15 \mathrm{wt} . \%$ content of flour waste were found to have higher burnout degree (up to $21.17 \%$ ) and mechanical endurance while having lower heating value (up to $6 \%$ ) and higher ignition temperatures (up to $24{ }^{\circ} \mathrm{C}$ ) compared to samples with no flour industry wastes.
\end{abstract}

\section{Introduction}

Production of electric energy is known to annually increase [1] as a result of growing population and development of industrial capacities. The analysis of the last 15 years revealed a decrease in the share of electricity generated by nuclear power and petroleum products [2]. However, slight increase was observed for hydro energy and renewable sources. At the same time, the power produced by gas-fired thermal power plants has significantly increased while coal power plants have shown the maximum increase up to $46 \%$ [1]. In the Russian Federation, more than $26 \%$ of power plants operate on coal [3, 4]. For majority of those thermal power plants, coal is imported fuel. The remoteness from coal deposits increases the cost of energy resources by 2 or more times for final consumer. When this type of fuel is burned, significant emissions of polluting anthropogenic substances occur, such as oxides of sulfur, carbon, nitrogen, fly ash and other [5,6]. Modern methods of harmful emission reducing are effective but with improper and inadequate maintenance, the efficiency of the filters used is lowered by more than $50 \%$ [7]. It leads to significant increasing of heat and power generation costs [7].

Possible solution for this problem may be a less expensive and more environmentally friendly composite fuel based on coal and sawmill waste (fine pine wood) [7]. The effectiveness of such fuels is achieved due to the carbon-neutrality of wood. It is the most common substance on the planet and its processing creates waste at colossal volumes. There is a

\footnotetext{
*Corresponding author: jankovsky@tpu.ru
} 
problem of storage and subsequent transportation of such composite fuels [7]. The production of fuel briquettes is often carried out by thermal method with the addition of binders.

But they significantly increase the cost of final product. Reducing cost of such fuels can be achieved by adding flour waste to improve the strength characteristics of coal and wood based fuel mixtures. The relevance of study in this field is significant and is supported by the energy strategy of Russia to 2035 [8].

\section{Experimental section}

For experimental studies 3B-grade coal of the Balakhtinsky deposit and waste products of timber produced by OOO Dzerzhinsky LPK, Tomsk, were used. Preparation of samples was carried out according to GOST 10742-71 with subsequent sieving according to GOST 3306-88. The particle size of the investigated coal samples was less than $80 \mu \mathrm{m}$, particle size of wood and flour were less than $200 \mu \mathrm{m}$ [9].

Three different compositions of fuel were prepared with different mass concentrations of components (Table 1). A mixture of coal and wood particles was placed into a galvanized drum with $5 \mathrm{~mm}$ diameter spherical grinding bodies of Pulverisette 6 mill at 1:1 weight ratio. The mixing process was carried out at $500 \mathrm{rpm}$ rotation frequency for 7 minutes [9].

Table 1. Composition of studied sample.

\begin{tabular}{|c|c|c|c|c|}
\hline \multirow{2}{*}{ Sample } & \multicolumn{4}{|c|}{ Volumetric fraction, \% } \\
\cline { 2 - 5 } & a & b & c & d \\
\hline Brown coal 3B & 47.5 & 45.0 & 42.5 & 50.0 \\
\hline Fine wood waste & 47.5 & 45.0 & 42.5 & 50.0 \\
\hline Flour waste & 5 & 10 & 15 & 0 \\
\hline
\end{tabular}

To form a composite fuel, a manual mechanical press was used. The obtained fuel samples are shown in fig. 1.

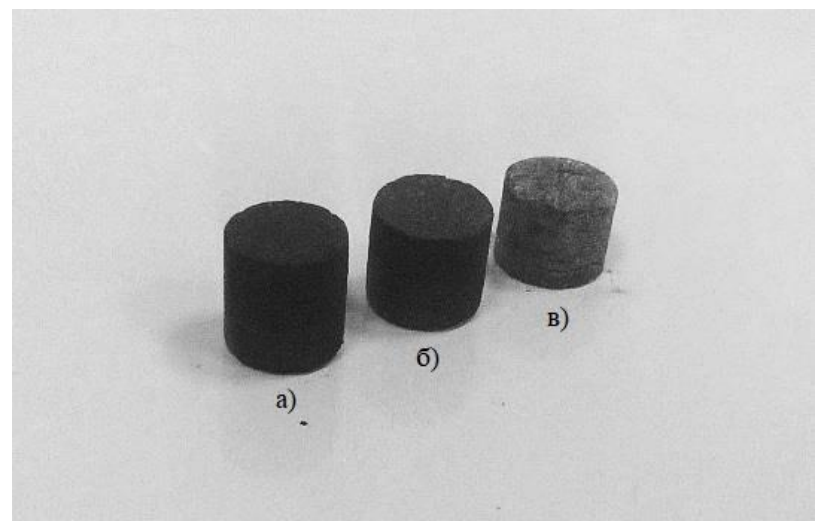

Fig. 1. Composite fuel appearance. Brown coal content to timber and flour waste ration: a) 47.5/47.5/5.0; b) 45.0/45.0/10.0; c) 42.5/42.5/15.0.

Technical analysis of the obtained samples of solid mixed fuels was carried out. [10, 12]

Thermogravimetric analysis was carried out to obtain experimental data on the degree of fuel burnup and the energy potential of solid mixed fuels [11, 12] using a combined TGDSC analyzer Netzsch STA 449 F3 Jupiter (Netzsch, Germany). Samples with $20 \mathrm{mg}$ mass were used for experiments. The heating rate was $10 \mathrm{~K} / \mathrm{min}$ and the maximal temperature was $1373 \mathrm{~K}[13,14]$. 


\section{Results and discussion}

A series of experiments was carried out to obtain experimental curves using differential thermal gravimetry. Obtained curves of DTG and DSC are presented in fig. 2 and 3.

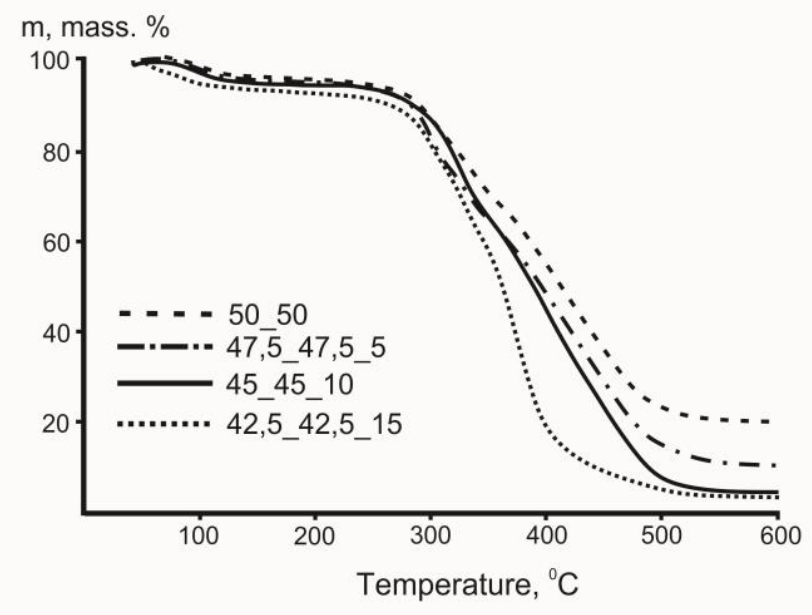

Fig. 2. TG curves of composite fuels with the different ratio of the main components (coal / wood / flour waste).

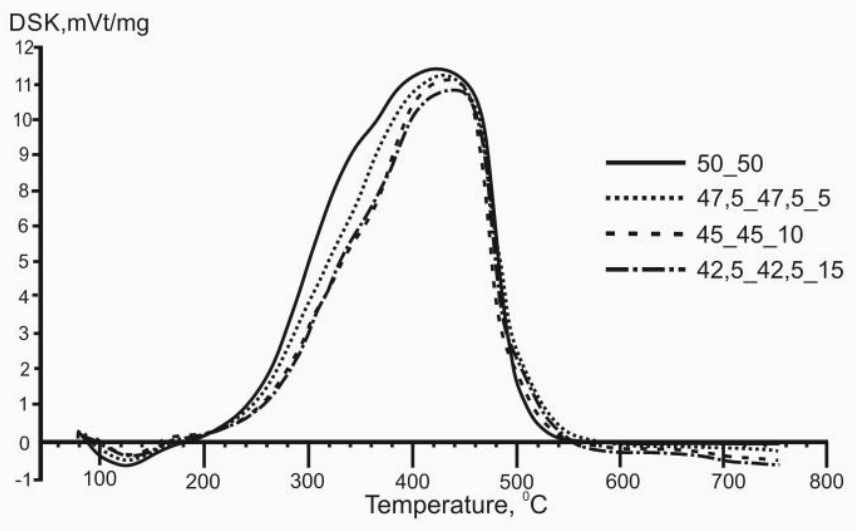

Fig. 3. DSC curves of composite fuels with the different ratio of main components (coal / wood / flour waste).

Analysis of fig. 2 allows to determine that with the increase of the third component (flour waste) from $0 \%$ to $15 \%$, the mixture burn up degree increases from $80.3 \%$ to $97.3 \%$. This effect appears due to decrease in the carbon content and an increase in the yield of volatiles in the composite fuel. The characteristic temperature of $10 \%$ sample mass loss for samples without flour content is higher than the corresponding characteristic temperature for the sample with $15 \%$ of flour waste by $24^{\circ} \mathrm{C}$ and is $292^{\circ} \mathrm{C}$.

DSC-curves in fig. 3 allow estimating energy release of the composite fuels. With an increase in the flour waste content to $15 \%$ in composite fuels the energy release is reduced by less than $6 \%$. The temperature of the thermal decomposition beginning remain at the level 
of the initial fuel based on coal and wood (without flour waste) as well as temperature of complete thermal decomposition is stays in same temperature range.

\section{Conclusion}

Composite fuels based on low-grade 3B brown coal of Balakhtinsky deposit with addition of fine-dispersed wood and flour industry waste were investigated. It was found that the addition of $15 \mathrm{wt} . \%$ of flour waste to initial fuel based on coal and wood improves strength properties of fuels and increases the degree of mixture burnup up to $97,3 \%$. However, such increase in the third component leads to a decrease in heat release by $6 \%$. It also moves temperature range of fuel thermal decomposition process into higher temperature area. The investigated fuel mixtures appear to have improved strength characteristics with lower energy spends for their preparation. They are also more environmentally friendly compared to coal. The results of the analysis make it possible to conclude that the using of composite fuels based on coal and wood with the addition of flour waste for combustion in the layer furnaces of boiler installations is promising.

The work was carried out with financial support of Minobrnauki RF in framework of project №13.7644.2017/BCH.

\section{References}

1. Dr. Fatih Birol Key World energy statistics (IEA, 2016)

2. E. Pavelyev, S. Lavrinenko, MATEC Web of Conf., 72, 01085 (2016)

3. S. Lavrinenko, P. Polikarpov, A. Matveeva, V. Martyshev, MATEC Web of Conf., 110, 01049 (2017)

4. A.I. Gabdullina, N.N. Galashov, S.A. Tsibulskiy, I.A. Asanov, A.S. Kiselev, MATEC Web Conf., 91, 01004 (2016)

5. N.V. Baranovskiy, A.E. Nee, EPJ Web Conf., 82, 01004 (2014)

6. N.V. Baranovskii, A.E. Ni, J.Eng.Thermophys., 87, 1438 (2014)

7. A.E. Nurpeiis, E. Orlova, K. Ponomarev, MATEC Web of Conf., 110, 01062 (2017).

8. A.N. Kozlov, D.A. Svishchev, G.I. Khudiakova, A.F. Ryzhkov, Solid Fuel Chem., 51, 205 (2017)

9. S. Jankovskiy, A. Tolokolnikov, V. Zaytsev, MATEC Web Conf., 110, 01080 (2017)

10. I.A. Dolgushin, Research and modernization of TPP scheme with CFB boiler to improve its efficiency and ecological characteristics (Moscow, 2014)

11. S.A. Jankovskiy, G.V. Kuznetsov, SPbPU scientific and technical bulletin. Fundamental and engineering science, 23, 29 (2017)

12. K. Larionov, I. Mishakov, A. Gromov, A. Zenkov, V. Glaktionov, MATEC Web Conf., 110, 01048 (2017)

13. K.B. Larionov, I.V. Mishakov, A.A. Gromov, A.V. Zenkov, MATEC Web Conf., 91, 01007 (2016)

14. A.A. Dekterev, P.V. Osipov, M.Y. Chernetskiy, A.F. Ryzhkov, Solid Fuel Chem., 51, 17 (2017)

15. M.Y. Chernetskiy, V.A. Kuznetsov, A.A. Dekterev, N.A. Abaimov, A.F. Ryzhkov, Thermophys. Aeromech., 23, 591 (2016) 